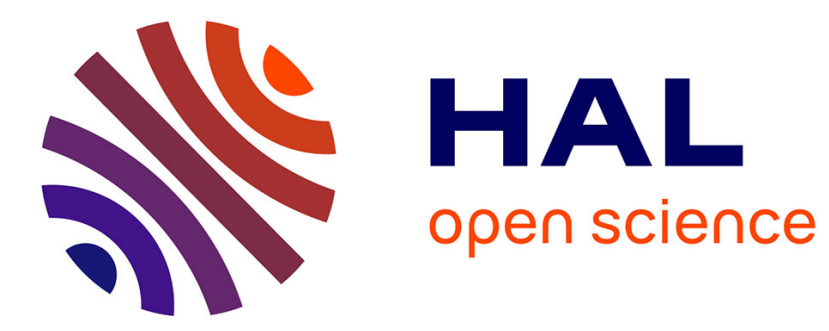

\title{
Templateless electrogeneration of polypyrrole nanostructures: impact of the anionic composition and $\mathrm{pH}$ of the monomer solution
}

Ahmed Fakhry, Françoise Pillier, Catherine Debiemme-Chouvy

\section{- To cite this version:}

Ahmed Fakhry, Françoise Pillier, Catherine Debiemme-Chouvy. Templateless electrogeneration of polypyrrole nanostructures: impact of the anionic composition and $\mathrm{pH}$ of the monomer solution. Journal of Materials Chemistry, 2014, 2, pp.9859-9865. 10.1039/c4ta01360c . hal-01095101

\author{
HAL Id: hal-01095101 \\ https://hal.science/hal-01095101
}

Submitted on 15 Dec 2014

HAL is a multi-disciplinary open access archive for the deposit and dissemination of scientific research documents, whether they are published or not. The documents may come from teaching and research institutions in France or abroad, or from public or private research centers.
L'archive ouverte pluridisciplinaire HAL, est destinée au dépôt et à la diffusion de documents scientifiques de niveau recherche, publiés ou non, émanant des établissements d'enseignement et de recherche français ou étrangers, des laboratoires publics ou privés. 


\title{
Templateless electrogeneration of polypyrrole nanostructures:
}

\section{Impact of the anionic composition and $\mathrm{pH}$ of the monomer solution.}

Ahmed Fakhry ${ }^{1,2}$, Françoise Pillier ${ }^{1,2}$, Catherine Debiemme-Chouvy ${ }^{1,2 *}$

${ }^{1}$ Sorbonne Universités, UPMC Univ Paris 06, UMR 8235

Laboratoire Interfaces et Systèmes Electrochimiques, F-75005 Paris, France

${ }^{2}$ CNRS, UMR 8235, LISE, CC 133, 4 place Jussieu, F-75005 Paris, France

\begin{abstract}
Different superhydrophilic polypyrrole nanostructures can be electrosynthezised in the presence of anions of weak acid (monohydrogenophosphate) and non-acidic anions (perchlorate) without the need for templates. Actually the type of nanostructures formed depends both on the concentration of anions at the electrode and on the interfacial $\mathrm{pH}$. Depending on the anion composition of the pyrrole aqueous solution the film electrogenerated under a given applied potential is either a very thin membrane $(10-20 \mathrm{~nm})$ consisting of overoxidized polypyrrole or a tridimensional film with oriented nanowire array or a network of more or less interconnected nanofibers. The formation of such nanostructures is explained by a side reaction which is water oxidation. Since this reaction is $\mathrm{pH}$-dependent, the $\mathrm{pH}$ of the pyrrole solution is one of the key parameter for the synthesis of such nanostructures. The reaction mechanism is discussed and compared to those proposed in the literature for nanofiber network electrosynthesis. Actually in the monomer solution, the role of the anions of weak acid is twofold. On the one hand they allow to limit the decrease of the interfacial $\mathrm{pH}$ during pyrrole oxidation and on the other hand to decrease the interfacial anion concentration, so that water oxidation takes place with formation of hydroxyl radicals and dioxygen nanobubbles.
\end{abstract}

Keywords: Polypyrrole, templateless nanostructure synthesis, electrochemical route, nanowires, nanofibers, interfacial $\mathrm{pH}$

\footnotetext{
${ }^{*}$ Corresponding author. Email : catherine.debiemme-chouvy@upmc.fr
} 


\section{Introduction}

Among the conducting organic polymers, polypyrrole (PPy) is one of the most widely used due to its high electronic conductivity, biocompatibility and good stability in air and aqueous media. These properties allow its use for various applications such as (bio)chemical sensors, ${ }^{1-}$ ${ }^{3}$ biomedical devices, ${ }^{4,5}$ batteries, ${ }^{6,7,8}$ fuel cells, ${ }^{9,} 10$ electrochemical supercapacitors, ${ }^{11,12,13}$ corrosion protection ${ }^{14,15}$ and so on. ${ }^{16,17}$ For all of these applications the structure of the polymer is important, and it is notably interesting to have nanostructures with very high specific surface. These materials can be synthesized in the presence or in the absence of templates. $^{18,19,20}$

Polypyrrole can be prepared by using either a chemical or an electrochemical route. To control over the location of the deposit and the polymer thickness, the electropolymerization can be considered as the main method. It is an attractive technique that allows the one-step formation of a polymer film onto the electrode surface. ${ }^{21,22}$ Whatever the method used, the oxidation of pyrrole (Py) leads to the formation of polypyrrole under its oxidized form, form doped with anions $\left(\mathrm{A}^{-}\right)$, according to the following reaction:

$$
\mathrm{nPy}+\gamma \mathrm{n} \mathrm{A}^{-} \rightarrow\left[(\mathrm{Py})_{\mathrm{n}}^{(\gamma \mathrm{n})+}, \gamma \mathrm{n} \mathrm{A}^{-}\right]+2(\mathrm{n}-1) \mathrm{H}^{+}+((2+\gamma) \mathrm{n}-2) \mathrm{e}^{-}
$$

where $\gamma$ stands for the doping level of the polymer, it is generally between 0.25 and 0.33 . From reaction (1) it should be noted on the one hand that the interfacial $\mathrm{pH}$ decreases since protons are released and on the other hand that the presence of anions is essential. Li has shown that the Py polymerization rate is directly proportional to the anion concentration of the monomer solution (for $\left[\mathrm{A}^{-}\right]<1 \mathrm{M}$ ). ${ }^{23}$

For electrochemical PPy synthesis, various parameters such as the applied potential or the anodic current, ${ }^{24}$ the concentration of monomer, ${ }^{25}$ the nature of the supporting electrolyte, ${ }^{26}$ 
and the nature of the working electrode ${ }^{27}$ have an influence on the growth kinetics and the final structure of the polymer. ${ }^{28,29}$ Polypyrrole nanostructures have been obtained using pyrrole solution containing either monohydrogenophosphate ${ }^{28}$ or mixing of monohydrogenophosphate and dihydrogenophosphate (phosphate buffer solution (PBS) $)^{30-35}$ or carbonate. $^{36,} 37$ For example, it has been shown that in the presence of only monohydrogenophosphate or carbonate anions, ultra thin overoxidized PPy films are formed. ${ }^{38,} 39,40$ In the presence of monohydrogenophosphate and low concentration of perchlorate ions oriented PPy nanostructures have been obtained. ${ }^{28}$

As far as the mechanism of formation of overoxidized PPy film is concerned, it has been reported that when only anions of weak acids (named weak-acid anions), such as monohydrogenophosphate, acetate, carbonate, monohydrogenocarbonate or tartrate, which confer a relatively high $\mathrm{pH}$ to the Py solution, are present in a pyrrole aqueous solution the electrooxidation of the monomers leads to a pinhole-free very thin $(\sim 10-20 \mathrm{~nm})$ nonconductive overoxidized polypyrrole (OPPy) film, under potentiostatic or potentiodynamic conditions. ${ }^{38}$ Actually this overoxidation is indirectly related to the release of protons at the electrode/solution interface during Py oxidation (Reaction 1). Indeed, the protons which are released during Py polymerization are captured by the weak-acid anions. Thus if the current is high, i.e. if a lot of protons are produced, at a moment very few or no anions are available at the electrode/solution interface so that the Py oxidation cannot occur anymore. If a high potential is applied at the electrode, water oxidation takes place leading to the generation of hydroxyl radicals which react with the already deposited PPy film resulting in its overoxidation:

$$
\begin{aligned}
& \mathrm{H}_{2} \mathrm{O} \rightarrow \mathrm{OH}^{\bullet}+\mathrm{H}^{+}+\mathrm{e}^{-} \\
& \mathrm{PPy}+\mathrm{x} \mathrm{OH}^{\bullet} \rightarrow \mathrm{OPPy}+\ldots
\end{aligned}
$$


However, when non-acidic anions such as perchlorate are added to a pyrrole solution containing a high concentration of $\mathrm{K}_{2} \mathrm{HPO}_{4}$ salt, polypyrrole nanowires (NWs) which are surrounded by OPPy are obtained. ${ }^{28}$ Under potentiostatic conditions, the length of the NWs is a function of the electrode polarization duration. In this case the polymeric film is conductive and superhydrophilic. Herein, we report for the first time on the influence of the perchlorate concentration of a pyrrole aqueous solution which contains a high concentration of monohydrogenophosphate ions $(0.2 \mathrm{M})$ on the electropolymerization process and its effects on the morphology of the films. Additionally, the influence of the $\mathrm{pH}$ of the pyrrole solution is also studied. The reaction mechanism which leads to the synthesis of nanostructure without the use of template or of chemical additives is also discussed and compared to those reported in the literature for electrosynthesis of polypyrrole nanofibers.

\section{Experimental section}

Pyrrole solution was distilled before use. Py solution, $\mathrm{K}_{2} \mathrm{HPO}_{4}, \mathrm{LiClO}_{4}, \mathrm{~K}_{3} \mathrm{Fe}(\mathrm{CN})_{6}$ and $\mathrm{K}_{4} \mathrm{Fe}(\mathrm{CN})_{6}$ salts were purchased from Aldrich. All the solutions were prepared with bidistilled water.

The electrochemical experiments were performed in a classical three-electrode electrochemical cell. A platinum wire was used as counter electrode and a saturated calomel electrode $(\mathrm{SCE})$ as the reference one. The working electrode was either $\mathrm{Pt}\left(\mathrm{S}=0.07 \mathrm{~cm}^{2}\right)$ or $\mathrm{Au} / \mathrm{glass}$ or a-CNx substrates for SEM observations. The pyrrole polymerization was conducted under potentiostatic conditions. The potentiostat used was an Autolab PGSTAT30 (Ecochemie).

After the PPy film electrogeneration, its superhydrophilic character was checked by performing the drop test. This consists on putting a small water droplet on the polypyrrole film and to check whether the drop spreads over the entire surface of the film or not. This test 
allows one to detect the presence of polypyrrole nanostructures as confirmed by scanning electron microspoy (SEM) observations. The film morphology was examined under a field emission gun scanning electron microscope (FEG-SEM), Ultra55 Zeiss, operating at $3 \mathrm{kV}$.

The chemical composition of the polymers was determined by X-ray photoelectron spectroscopy (XPS). The XPS measurements were performed on a VG ESCALAB 250i-XL spectrometer using monochromatic $\mathrm{Al} \mathrm{K} \alpha$ radiation as the $\mathrm{X}$-ray source. The survey spectra were recorded with a pass energy (PE) of $100 \mathrm{eV}$, in the constant analyzer energy mode. For the detection of trace of elements (doping anions of the PPy film), the PE was fixed at $50 \mathrm{eV}$ and the number of scans was 49 . The detection angle was $90^{\circ}$ with respect to the plane of the sample.

\section{Results and discussion}

Using a pyrrole solution containing $0.2 \mathrm{M} \mathrm{K}_{2} \mathrm{HPO}_{4}, \mathrm{pH}$ around 8.9, the electropolymerization of the monomer was performed under potentiostatic conditions, at $0.78 \mathrm{~V} / \mathrm{SCE}$. In order to investigate the influence of the presence of non-acidic anions on the electrochemical process, several experiments were conducted using various concentrations of $\mathrm{LiClO}_{4}$, from $10^{-4} \mathrm{M}$ to $5.10^{-2}$ M. Figure SI-1 shows the chronoamperograms recorded during these experiments. From this figure, it is obvious that the anodic current (Py polymerization rate) depends on the perchlorate concentration even though the initial concentration of monohydrogenophosphate ions is high.

For perchlorate concentrations lower than $8.10^{-4} \mathrm{M}$, the anodic current which is high at the very beginning of the polarization of the electrode decreases rapidly up to a very low and nearly constant value (curves $\mathrm{A}$ and $\mathrm{B}$ in Figure SI-1). The shape of these chronoamperometric curves is similar to the one obtained in the absence of perchlorate in the medium, also the anodic charge $(\mathrm{Q}=\mathrm{It})$ is similar, it is about $0.015 \mathrm{C} \mathrm{cm}^{-2}$ (after $600 \mathrm{~s}$ of 
polarization). ${ }^{28} 40$ The films electrogenerated under these conditions are overoxidized (nonconductive) films.

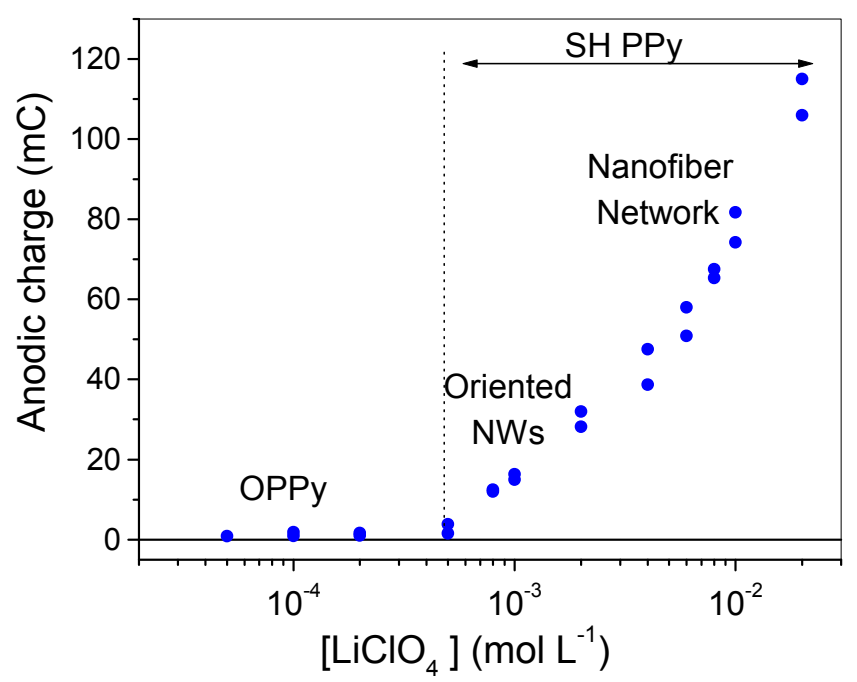

Figure 1: Anodic charge vs. perchlorate concentration of the Py solution. Charge passes though a Pt electrode polarized at $0.78 \mathrm{~V} / \mathrm{SCE}$ for $600 \mathrm{~s}$. Electrolyte: $\mathrm{LiClO}_{4}+0.2 \mathrm{M} \mathrm{K}_{2} \mathrm{HPO}_{4}$ + 0.15 M Py. OPPy: overoxidized PPy. SH PPy: superhydrophilic PPy electrodeposit.

For $\mathrm{LiClO}_{4}$ concentrations higher than $5.10^{-4} \mathrm{M}$, the shape of the chronoamperometric curves is different from the previous ones. First, the anodic current decreases rapidly too but after it increases more or less slowly indicating that the films are at least partially conductive. Moreover these films are superhydrophilic according to the water droplet test indicating that they are nanostructured.

All these findings are summarized in Figure 1 that shows the variation of the anodic charge according to the perchlorate concentration of the pyrrole solution $(0.15 \mathrm{M}$ Py $+0.2 \mathrm{M}$ $\mathrm{K}_{2} \mathrm{HPO}_{4}$ ). Even if the perchlorate concentration is low in comparison with the initial monohydrogenophosphate one its influence on the anodic charge is important. Indeed, for given experimental conditions, the higher is the perchlorate ion concentration the higher is the anodic charge. After 600 seconds of polarization at $0.78 \mathrm{~V} / \mathrm{SCE}$, for a perchlorate concentration of $0.1 \mathrm{mM}$ the anodic charge is $0.9 \mathrm{mC}$ whereas for a concentration of $20 \mathrm{mM}$ 
the charge is more than a hundred time higher, about $100 \mathrm{mC}$. However, it is noteworthy that when the PPy films are electrogenerated in the same experimental conditions but in the absence of $\mathrm{HPO}_{4}{ }^{2-}$ i.e. just in the presence of $0.15 \mathrm{M}$ pyrrole and $0.02 \mathrm{M} \mathrm{LiClO}_{4}$, the anodic charge is substantially higher, equals to $800 \mathrm{mC}$ (after $600 \mathrm{~s}$ at $0.78 \mathrm{~V} / \mathrm{SCE}$ ), and the shape of the chronoamperometric curve is different (not shown). The electrode is coated with a very thick black film which is not superhydrophilic. Therefore one can conclude that the film obtained under this condition (without $\mathrm{K}_{2} \mathrm{HPO}_{4}$ ) is not nanostructured.
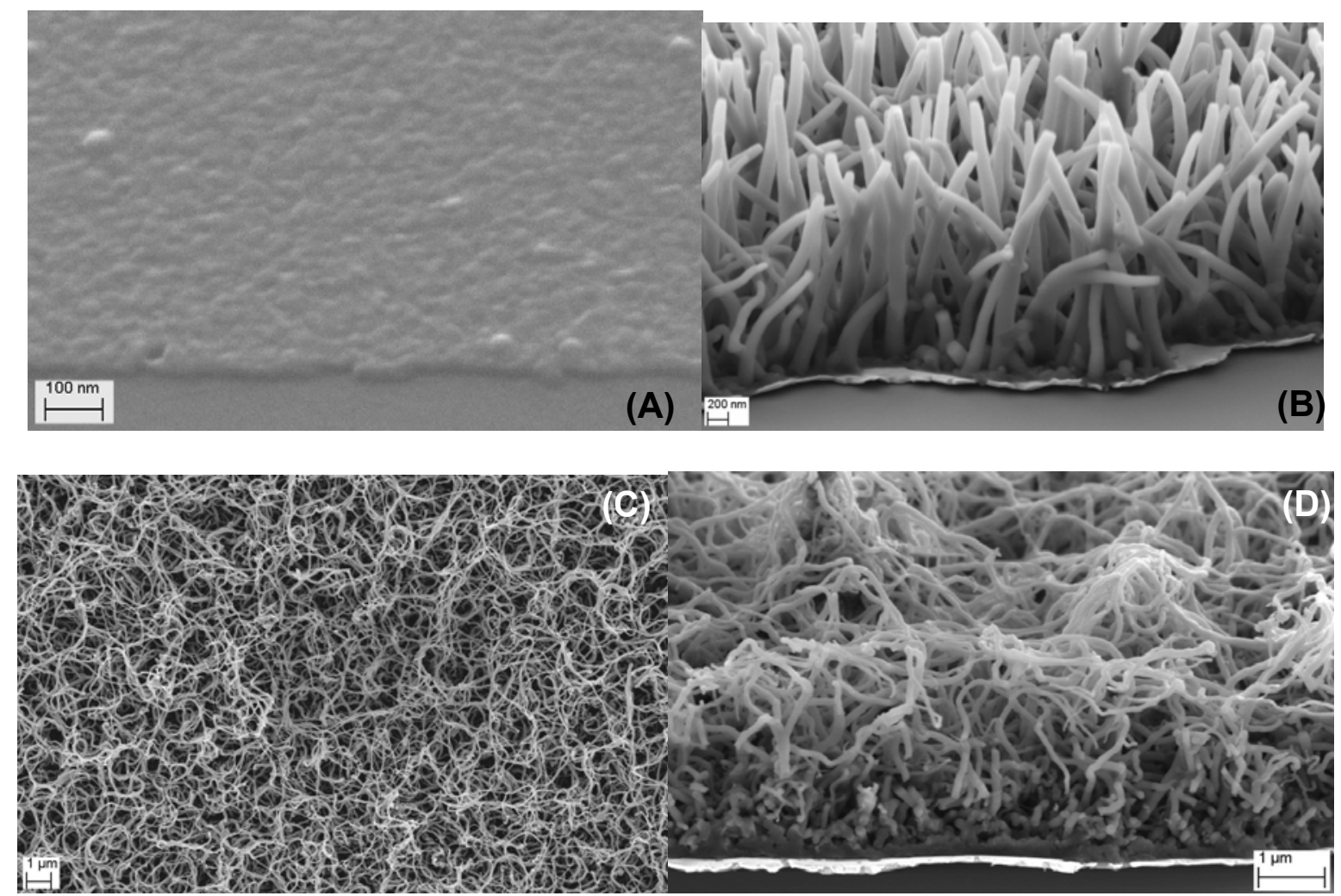

Figure 2: SEM images from PPy films electrogenerated in (A) $10^{-4} \mathrm{M} \mathrm{LiClO}_{4}+0.2 \mathrm{M}$ $\mathrm{K}_{2} \mathrm{HPO}_{4}+0.15 \mathrm{M} \mathrm{Py} ;$ (B) $10^{-3} \mathrm{M} \mathrm{LiClO}_{4}+0.2 \mathrm{M} \mathrm{K}_{2} \mathrm{HPO}_{4}+0.15 \mathrm{M} \mathrm{Py} ;(\mathrm{C}, \mathrm{D}) 5.10^{-2} \mathrm{M}$ $\mathrm{LiClO}_{4}+0.2 \mathrm{M} \mathrm{K}_{2} \mathrm{HPO}_{4}+0.15 \mathrm{M}$ Py at $0.78 \mathrm{~V} / \mathrm{SCE}$ for $600 \mathrm{~s}(\mathrm{~A}, \mathrm{C}, \mathrm{D})$ or $1000 \mathrm{~s}$ (B). (A, B, D) cross section, $\theta=65^{\circ}$. (C) Top view. Substrates: (A) a-CNx, (B, C, D) Au/mica. Scale bars: (A) $100 \mathrm{~nm}$, (B) $200 \mathrm{~nm},(\mathrm{C}, \mathrm{D}) 1 \mu \mathrm{m}$. 
Notice that the same experiments were done applying two different potentials, $0.75 \mathrm{~V} / \mathrm{SCE}$ and $0.8 \mathrm{~V} / \mathrm{SCE}$. The results are similar except that the anodic currents are higher for the higher applied potential (not shown). The shape of the current-time curves remains identical.

The SEM images reported in Fig. 2 allow one to compare the different morphologies of PPy films obtained under the same experimental conditions except the perchlorate concentration of the pyrrole solution.

Actually, for very low concentration of $\mathrm{LiClO}_{4}$ (below $8.10^{-4} \mathrm{M}$ ), ultra thin non-conductive overoxidized polypyrrole films are obtained (Fig. 2A). For $\mathrm{LiClO}_{4}$ concentrations higher than $8.10^{-4} \mathrm{M}$, the films are conductive and superhydrophilic as previously described. For intermediate perchlorate concentrations, between $8.10^{-4} \mathrm{M}$ and $2.10^{-3} \mathrm{M}$, well oriented nanowires (NWs) are obtained (Fig. 2B) whereas for the highest concentrations $\left(>2.10^{-3} \mathrm{M}\right)$ the PPy nanostructures are much longer and are more or less interconnected leading to networks (Figs. 2C and 2D). These SEM images show that with increasing perchlorate ion concentration, the density and length of the polypyrrole nanostructures increase which is in good agreement with the increase of the anodic charge (Fig. 1). It is clear that with increasing the perchlorate concentration, the nanostructures change from oriented polypyrrole nanowires to polypyrrole networks consisting of very long nanofibers more or less interconnected. The length of the PPy nanostructures can be monitored just by varying the electrode polarization duration. Indeed, for perchlorate concentrations higher than $510^{-4} \mathrm{M}$, the anodic charge increases with the polarization time (see Fig. SI-2) indicating that the polymer is continuously electrogenerated. It has been shown that in the presence of $1 \mathrm{mM}$ perchlorate the NW growth rate is constant with time about $0.8 \mathrm{~nm} \mathrm{~s}^{-1}$ (at $\left.0.75 \mathrm{~V} / \mathrm{SCE}\right){ }^{28}$ 

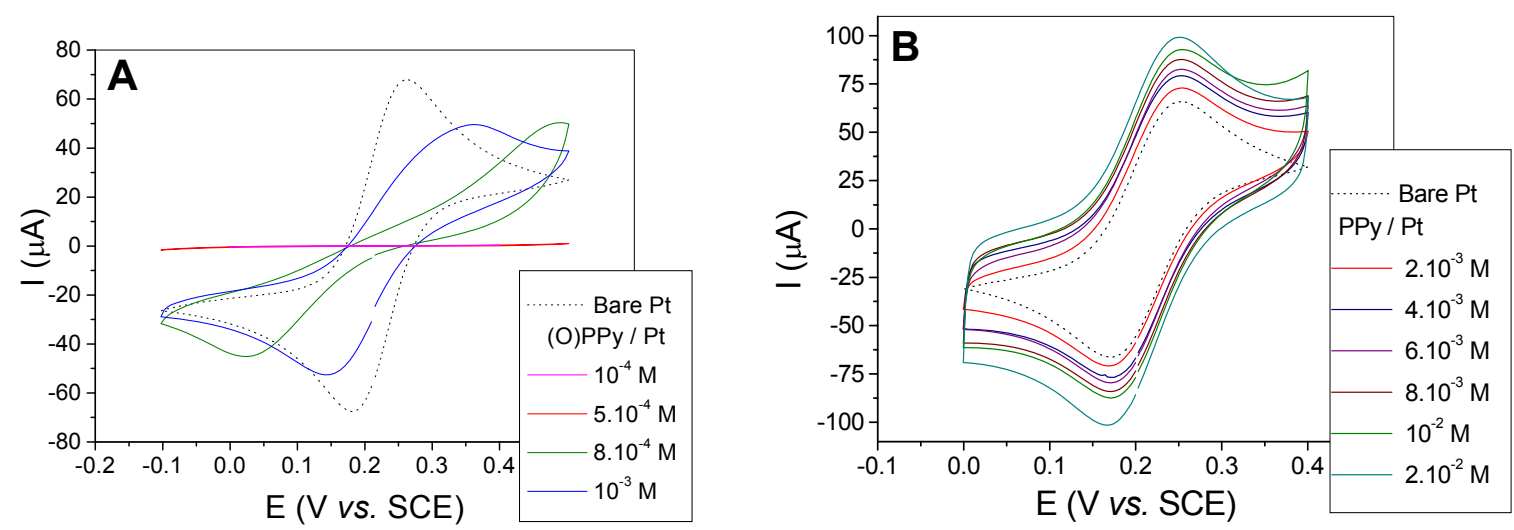

Figure 3: Cyclic voltamograms at a Pt electrode coated with a polypyrrole film obtained under potentiostatic conditions $(0.78 \mathrm{~V} / \mathrm{SCE})$ in $0.15 \mathrm{M} \mathrm{Py}+0.2 \mathrm{M} \mathrm{K}_{2} \mathrm{HPO}_{4}+\mathrm{LiClO}_{4}$ aqueous solution. $\mathrm{LiClO}_{4}$ concentrations are indicated in the graph $\left(\mathrm{A}: 10^{-4}\right.$ to $10^{-3} \mathrm{M} ; \mathrm{B}: 210^{-3} \mathrm{M}$ to 2 $\left.10^{-2} \mathrm{M}\right)$. Electrolyte: $10^{-2} \mathrm{M} \mathrm{Fe}(\mathrm{CN})_{6}^{4-/ 3-}+0.5 \mathrm{M} \mathrm{KCl}$. Potential scan rate : $10 \mathrm{mV} \mathrm{s}^{-1}$.

The nature of the polymeric films was confirmed by the cyclic voltametry performed in the presence of a rapid monoelectronic redox system $\left(\mathrm{Fe}(\mathrm{CN})_{6}^{4-/ 3-}\right.$ in $0.5 \mathrm{M} \mathrm{KCl}$ aqueous solution). The current-potential responses are reported in Figure 3. For the films obtained with perchlorate concentrations lower than $8.10^{-4} \mathrm{M}$, the voltammograms are flat, no currents are detected (see Fig. 3A), the oxidation and the reduction of the redox probe do not occur. This confirms that the electrode is coated with a compact insulator film i.e. with an overoxidized PPy film. Indeed, as previously mentioned, same result has been obtained for films electrogenerated in pyrrole solution containing only $\mathrm{HPO}_{4}{ }^{2-}$ anions. ${ }^{38,40}$ On the contrary, for $\mathrm{LiClO}_{4}$ concentration higher than $8.10^{-4} \mathrm{M}$ (Fig. 3B), anodic and cathodic currents are detected and their values increase with the perchlorate concentration used for the electrogeneration of the PPy deposit on the Pt electrode (see Fig. 4). For comparison, the curve recorded at a bare Pt electrode is shown too. 


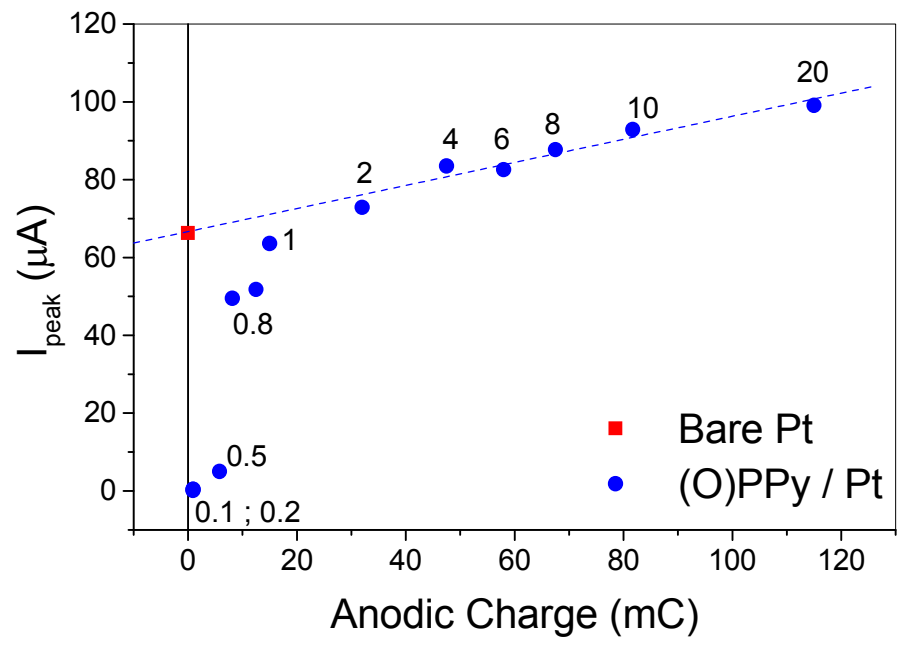

Figure 4: Anodic current peak in $10^{-2} \mathrm{M} \mathrm{Fe}(\mathrm{CN})_{6}{ }^{4-/ 3-}+0.5 \mathrm{M} \mathrm{KCl}$ aqueous solution vs. the anodic charge due to (O)PPy film electrogeneration at $0.78 \mathrm{~V} / \mathrm{SCE}$ for $600 \mathrm{~s}$ in $\mathrm{LiClO}_{4}$ (concentrations in $\mathrm{mM}$ are indicated in the graph) $+0.2 \mathrm{M} \mathrm{K}_{2} \mathrm{HPO}_{4}+0.15 \mathrm{M}$ Py solution. Data are from Fig. 3.

The (O)PPy films were also characterized by XPS. For the PPy 3D structure, this analysis allows notably to determine the nature of the doping anions $\left(\mathrm{ClO}_{4}{ }^{-}\right.$and/or $\left.\mathrm{HPO}_{4}{ }^{2-}\right)$ and the ratio between them if exists. Figure 5 shows the XPS survey spectra obtained for deposits electrogenerated in the presence of $0.1 \mathrm{mM}$ (Fig. 5A) and $5 \mathrm{mM}$ (Fig. 5B) of the perchlorate ion. For the lower concentration no $\mathrm{Cl}(208 \mathrm{eV})$ or $\mathrm{P}(104 \mathrm{eV})$ contribution are detected in the survey spectrum (Fig. 5-A). The signals recorded in the energy range of the 

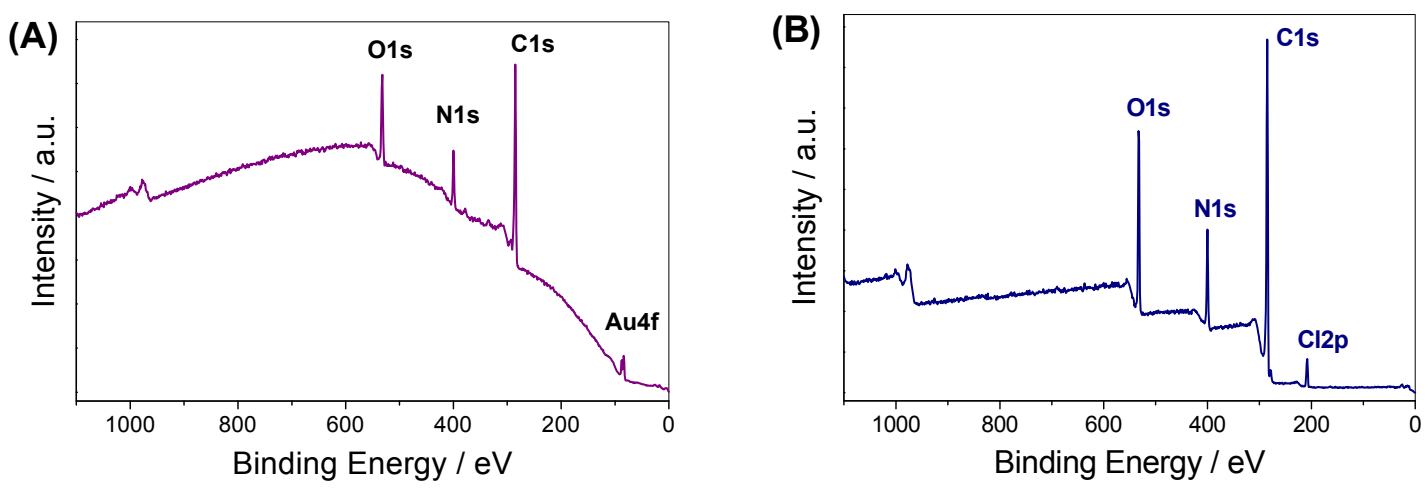

Figure 5: XPS survey spectra obtained from films electrogenerated in $0.15 \mathrm{M} \mathrm{Py}+0.2 \mathrm{M}$ $\mathrm{K}_{2} \mathrm{HPO}_{4}+10^{-4} \mathrm{M}(\mathrm{A})$ or $510^{-3} \mathrm{M}(\mathrm{B}) \mathrm{LiClO}_{4}$, at $0.78 \mathrm{~V} / \mathrm{SCE}$ for 600 seconds, on $\mathrm{Au} / \mathrm{mica}$ substrates.

P2p and C12p do not show any features (49 scans, pass energy (PE) $50 \mathrm{eV}$ ). This finding confirms that the films are overoxidized i.e. they are dedoped, they do not contain any anions. Moreover, the shape of the background of the survey spectrum confirms that the film is nonconductive (overoxidized). It should be noted that the gold substrate is detected (Au4f: $82 \mathrm{eV}$ ) this implies that the OPPy film is very thin about $10 \mathrm{~nm}$, in good agreement with the SEM image shown in Fig. 2A.

For the highest perchlorate concentration used to electrogenerate the PPy film, the $\mathrm{Cl} 2 \mathrm{p}$ contribution is clearly visible in the survey spectrum (Fig. 5-B). In this spectrum no $\mathrm{P}$ is detected. However the $\mathrm{P} 2 \mathrm{p}$ range exhibits a slight contribution. Actually the integration of $\mathrm{Cl} 2 \mathrm{p}$ and $\mathrm{P} 2 \mathrm{p}$ peaks (both recorded with a PE of $50 \mathrm{eV}$ ) indicates that the concentration of each element in the PPy nanostructures is about $96 \%$ of $\mathrm{Cl}$ and $4 \%$ of $\mathrm{P}$. Therefore under our experimental conditions, logically, the polymer is doped with the anions without acid-base properties i.e. which are still ionized because they do not capture the protons released during pyrrole oxidation (reaction 1) on the contrary to weak-acid anions.

The nature of the anions and the release of protons during the oxidation of pyrrole (Reaction 1) are important and decisive for the elaboration of polypyrrole nanostructures. Indeed we 
assume that the nanostructuration of the films is due to the oxidation of some water molecules which leads to the formation of hydroxyl radicals (Reaction 2). These radicals can react with the already deposited film to overoxidize it or with themselves, leading to $\mathrm{H}_{2} \mathrm{O}_{2}$ that is further oxidized to $\mathrm{O}_{2}$ :

$$
\begin{aligned}
& 2 \mathrm{OH}^{\bullet} \rightarrow \mathrm{H}_{2} \mathrm{O}_{2} \\
& \mathrm{H}_{2} \mathrm{O}_{2} \rightarrow \mathrm{O}_{2}+2 \mathrm{H}^{+}+2 \mathrm{e}^{-}
\end{aligned}
$$

In the presence of anions having no acid-base property (perchlorate ions in the present case) when their concentration in the electrolytic media is sufficient, the increase of the anodic current over time implies the presence of conductive areas on the formed film. Considering all our experimental results, we have suggested that these areas are present due to the formation of $\mathrm{O}_{2}$ nanobubbles which protect the polypyrrole film from the hydroxyl radicals avoiding its overoxidation. This allows the electrochemical growth of the polypyrrole nanowires. This mechanism is summarized in the scheme presented in Figure 6.

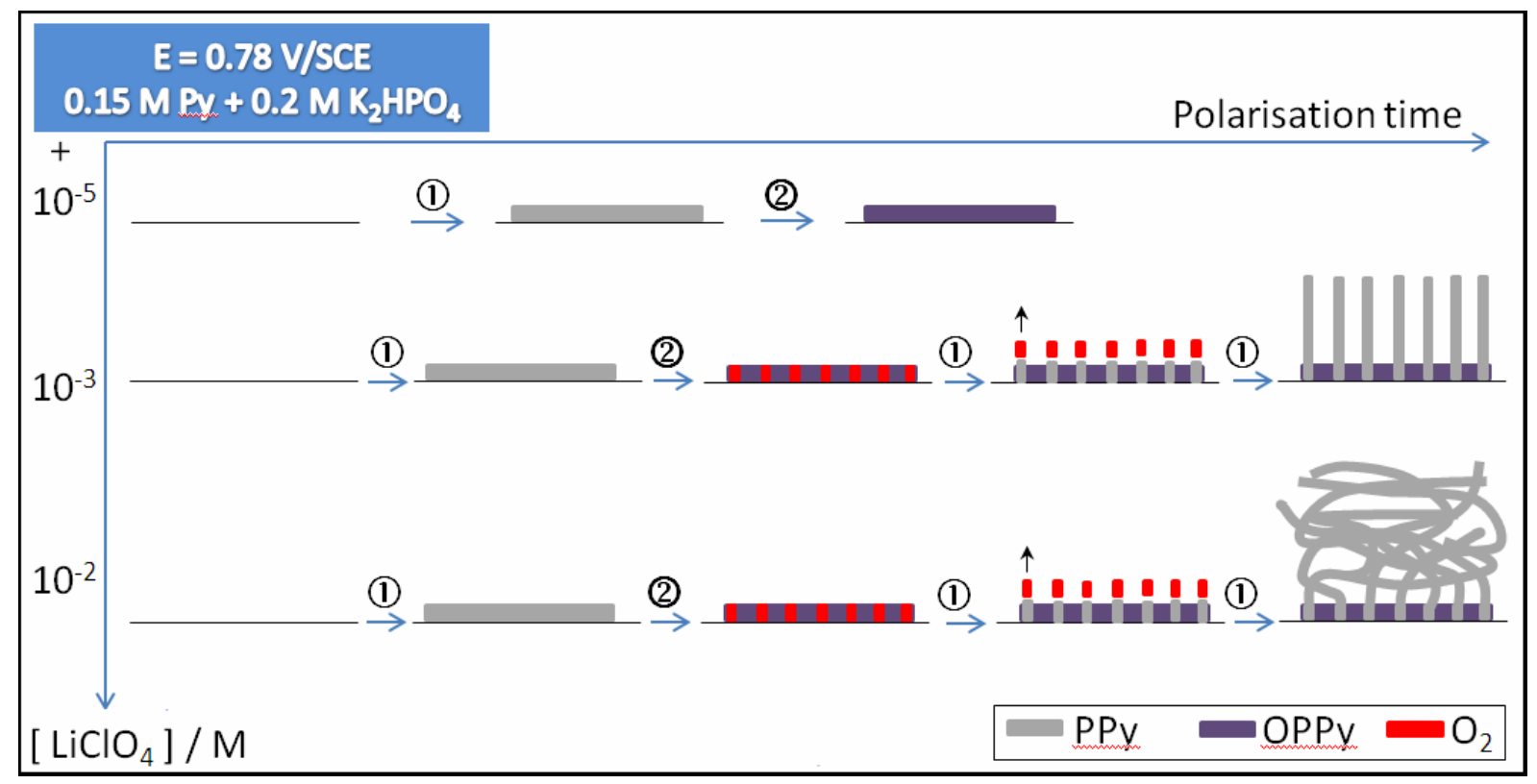

Figure 6: Schematic model showing the process which takes place depending on the perchlorate concentration of a $0.15 \mathrm{M} \mathrm{Py}+0.2 \mathrm{M} \mathrm{K}_{2} \mathrm{HPO}_{4}$ solution on the electrode polarized at $0.78 \mathrm{~V} / \mathrm{SCE}$. (1): Py oxidation ; (2): water oxidation $\left(\mathrm{OH} \bullet\right.$ and $/$ or $\mathrm{O}_{2}$ production). 
Obviously, when the rate of formation of hydroxyl radicals is very slow, the reaction of PPy overoxidation is the predominant one with respect to reaction (4) which is a second-order reaction with respect to the hydroxyl radical. It should be emphasized that the standard potential $\left(\mathrm{E}^{0}\right)$ of water oxidation reaction is a function of the $\mathrm{pH}$ of the medium: $\mathrm{E}^{0}=0.99$ $0.06 \mathrm{pH} \mathrm{V} / \mathrm{SCE}$, at $25^{\circ} \mathrm{C}$. Thus, for an applied potential of $0.78 \mathrm{~V} / \mathrm{SCE}$, from a kinetic point of view, water oxidation can occur if the interfacial $\mathrm{pH}$ is higher than 3.5 , at $25^{\circ} \mathrm{C}$.
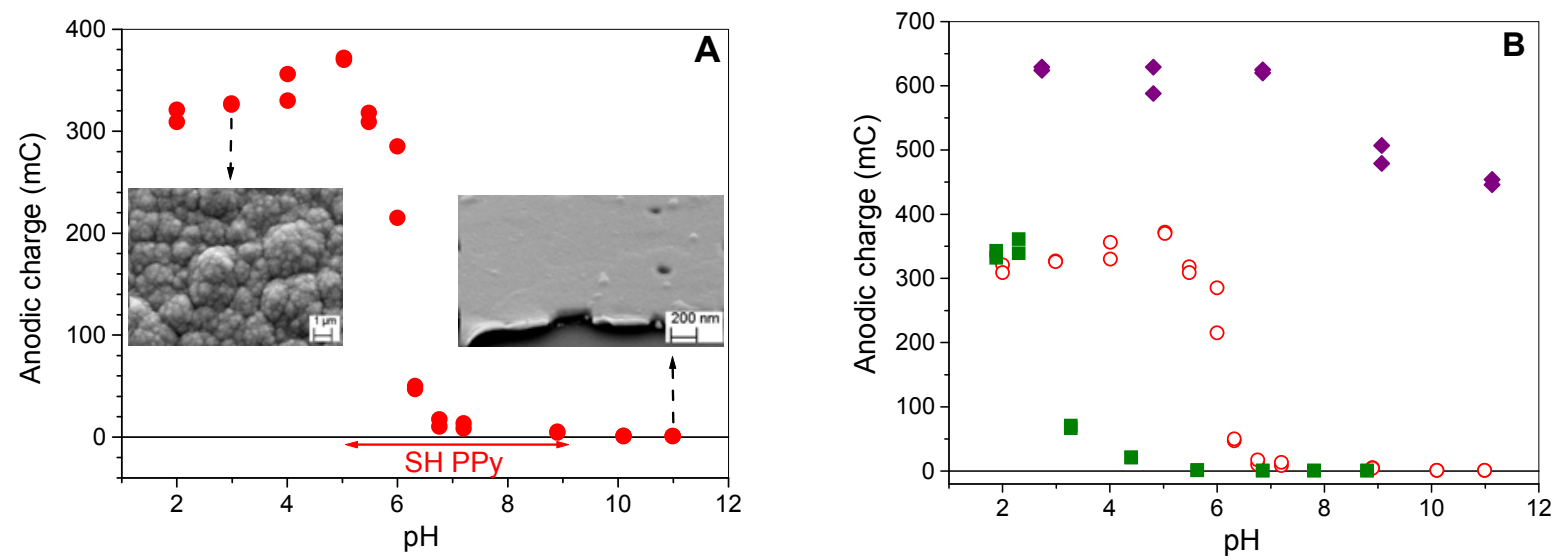

Figure 7: Anodic charge vs. $\mathrm{pH}$ of the Py solution after $600 \mathrm{~s}$ of polarization at $0.78 \mathrm{~V} / \mathrm{SCE}$. Electrolyte: A: $0.15 \mathrm{M}$ Py $+0.2 \mathrm{M} \mathrm{K}_{2} \mathrm{HPO}_{4}+10^{-3} \mathrm{M} \mathrm{LiClO}_{4} \pm \mathrm{H}_{3} \mathrm{PO}_{4}$ or $\mathrm{KOH}$ to adjust the

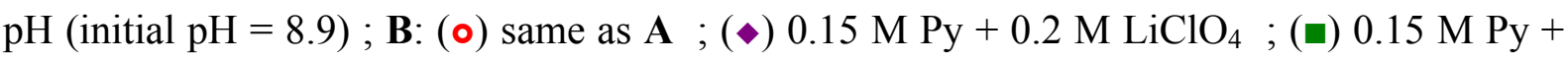
$0.2 \mathrm{M} \mathrm{K}_{2} \mathrm{HPO}_{4}$. Inset A: SEM images of the films obtained at $\mathrm{pH} 3$ and 11 (Substrate: Au/mica). Scale bars: $1 \mu \mathrm{m}$ (pH 3), 200 nm (pH 11). SH PPy: superhydrophilic PPy film.

Additional experiments have been performed to confirm that the PPy nanostructures are formed due to the oxidation of water i.e. because on the one hand the interfacial $\mathrm{pH}$ is high and on the other hand the Py polymerization cannot occur due to the very low interfacial anion concentration. Actually it has been verified that if the $\mathrm{pH}$ of the pyrrole solution is decreased or increased by addition of $\mathrm{H}_{3} \mathrm{PO}_{4}\left(\mathrm{pKa}_{1}=2.1, \mathrm{pKa}_{2}=7.2, \mathrm{pKa}_{3}=12.7\right)$ or $\mathrm{KOH}$, respectively the pyrrole oxidation rate changes drastically. The results are shown in Figure 7. 
In the presence of $0.2 \mathrm{M}$ monohydrogenophosphate anions and $1 \mathrm{mM}$ perchlorate anions, for pyrrole solutions of $\mathrm{pH}$ lower than 4 , after polarization for 600 seconds at $0.78 \mathrm{~V} / \mathrm{SCE}$, the resulting anodic charge is high. The PPy films prepared under these experimental conditions have a classical cauliflower-like structure (see Fig. 7A). On the contrary, for Py solutions having very high $\mathrm{pH}(>9)$, the resulting anodic charge is extremely low and OPPy films are formed (Fig. 7A). Besides, in order to confirm the influence of the nature of the anions similar experiments have been conducted in the presence of only perchlorate anions. In this case the influence of the $\mathrm{pH}$ is low, the anodic charge is persistently high (diamond scatters, Fig. 7B) and the films are not superhydrophilic i.e. they are not nanostructured. In the presence of only phosphates as anions in the Py solution (square scatters, Fig. 7B), and when the $\mathrm{pH}$ is lower than 4 (pHs at which water oxidation does not occur), conductive PPy films which are not superhydrophilic are electrogenerated. All these findings are in very good agreement with the mechanism proposed in Fig. 6.
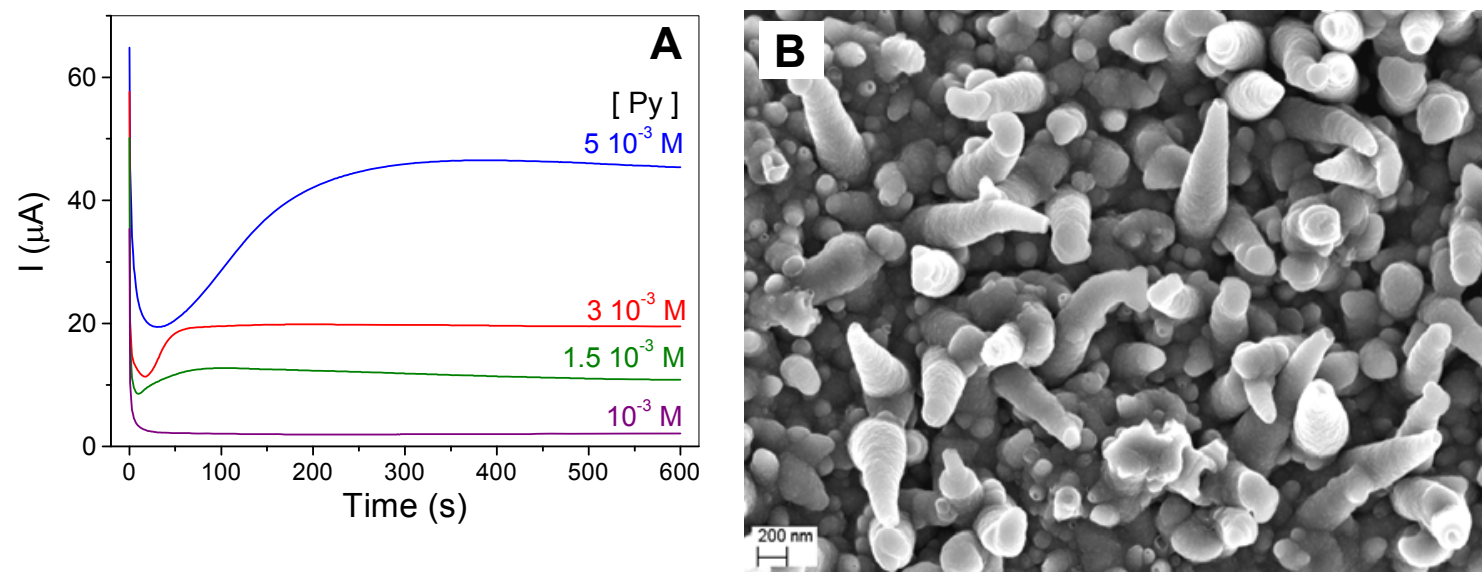

Figure 8: A: Current density vs. time a Pt electrode $\left(\mathrm{S}=0.07 \mathrm{~cm}^{2}\right)$ polarized at $0.75 \mathrm{~V} / \mathrm{SCE}$ in $0.2 \mathrm{M} \mathrm{LiClO}_{4}+$ Py aqueous solution. Py concentrations are indicated in the graph. Anodic charge: $1.3 \mathrm{mC}(1 \mathrm{mM}) ; 7 \mathrm{mC}(1.5 \mathrm{mM}) ; 11.5 \mathrm{mC}(3 \mathrm{mM}) ; 24.3 \mathrm{mC}(5 \mathrm{mM})$. B: SEM image of a PPy film electrogenerated in $510^{-3} \mathrm{M}$ Py $+0.2 \mathrm{M} \mathrm{LiClO}_{4}$ aqueous solution at 0.75 V/SCE for 300s. Scale bar: $200 \mathrm{~nm}$. 
Taking into account this mechanism, under a high applied potential, another way to limit the Py electrooxidation so that water oxidation takes place is to use a low pyrrole concentration. Then, in the case of a high concentration of non-acidic anion (perchlorate) and low concentration of pyrrole, PPy nanostructures should be obtained. Preliminary results shown in Figure 8 indicate that it is the case.

The synthesis of different PPy nanostructures is reported in the literature using various electrolytes and electrochemical methods. Different formation mechanisms of these nanostructures have been proposed including the use of gelatin molecules as templates to guide the formation of PPy nanostructures, the formation of nuclei on the surface of the working electrode at the beginning of the polymerization and the formation of micelles which can act as soft-templates.

PPy nanofibers have also been electrogenerated at $0.75 \mathrm{~V} / \mathrm{SCE}$ for $200 \mathrm{~s}$ in a phosphate buffer solution $(\mathrm{pH}=6.9)$ containing gelatin (from 0.002 to $0.02 \mathrm{wt} \%$ ), $0.07 \mathrm{M} \mathrm{LiClO}_{4}$ and $0.15 \mathrm{M}$ pyrrole at $60^{\circ} \mathrm{C}^{30}$ The authors suggested that the gelatin molecules act as a soft-template. Using gelatin we have obtained the same results. However similar structures have been also obtained without addition of gelatin in the Py solution $(0 \%$ gelatin: $\mathrm{Q}=36.8 \mathrm{mC} ; 0.002 \%$ gelatin: $\mathrm{Q}=23.6 \mathrm{mC} ; 0.02 \%$ gelatin: $\mathrm{Q}=18.9 \mathrm{mC}$ ) (see current-time curves and SEM images in Fig. SI-3). Therefore, we think that the mechanism proposed herein (Figure 6) is applicable to explain the nanostructure formation with or without gelatin. One can notice from Fig. SI-3 that in the presence of gelatin the Py polymerization rate is lower. This is likely due to an increase of the Py solution viscosity which leads to a decrease of the diffusion rate of the species from the bulk of the solution to the electrode. 
Another example concerns the synthesis of PPy nanofibers which were electrosynthesized by the use of normal pulse voltammetry (a series of potential pulses was imposed from -0.05 to $0.75 \mathrm{~V} / \mathrm{SCE}) .{ }^{31}$ In this case, the pyrrole monomers were dissolved in $0.2 \mathrm{M}$ PBS containing $0.1 \mathrm{M} \mathrm{LiClO}_{4}$. When the anodic potential was applied, the pyrrole monomers are polymerized and converted to PPy fiber at the electrode/solution interface and during the cathodic polarization, polymerization stops and PPy changes from oxidized state to the reduced state. The authors suggested that when the potential varies from cathodic to anodic, PPy nuclei are formed on the electrode surface and then, as the polymerization proceeds, these nuclei continuously grow together. However it has been noted by the authors that using classical cyclic voltammetry method ( 0 to $0.75 \mathrm{~V} / \mathrm{SCE}, 100$ cycles, potential scan rate of $\left.50 \mathrm{mV} \mathrm{s}^{-1}\right)$ PPy nanostructures were also obtained. The same mechanism was suggested for obtaining PPy nanowires in a solution containing phosphate buffer and organic sulfonic acids such as ptoluenesulfonic acid. ${ }^{34}$

PPy films having hollow structures have also been prepared under galvanostatic conditions (5 $\mathrm{mA} \mathrm{cm}{ }^{-2}$ ) in p-toluenesulfonate alkaline pyrrole solution $(\mathrm{pH}=9) .{ }^{41}$ Under the same experimental conditions but at $\mathrm{pH} 1.5$, it has been observed that the PPy films have classical cauliflower-like morphology. The authors have proposed that the growth mechanism implies the formation of micelles which can act as a template with the assistance of hydroxyl ions. A similar mechanism has been proposed concerning the formation of PPy conical nanocontainers from pyrrole aqueous solution $(\mathrm{pH}=6)$ containing $40 \mathrm{mM}$ D-camphorsulfonic acid and $1 \mathrm{mM} \mathrm{NaCl}{ }^{32}$

Finally similar superhydrophilic polypyrrole nanofibers have been obtained by Li et al. ${ }^{35}$ using an aqueous solution containing $0.1 \mathrm{M} \mathrm{Py}, 0.07 \mathrm{M} \mathrm{LiClO}_{4}$ and $0.2 \mathrm{M}$ PBS (pH 6.8) 
under potentiostatic conditions $(0.8 \mathrm{~V} / \mathrm{SCE})$. It was proposed that the presence of hydrogen bonding between phosphate anions and pyrrole oligomers is essential to produce nanostructures. Systematic investigations have indicated that a relatively high concentration of PBS, high $\mathrm{pH}$ and low oxidation potential favor the formation of PPy nanofibers.

Therefore, the formation mechanism we propose in this study (Fig. 6) perfectly allows one to explain the electrosynthesis of PPy nanostructures and can be an interesting compromise to the various mechanisms proposed in the literature.

\section{Conclusion}

Different polypyrrole nanostructures were obtained by the electropolymerization of pyrrole in the presence of both monohydrogenophosphate and perchlorate ions which are weak-acid anions and non-acidic anions, respectively. The influence of different parameters were studied especially that of the concentration of perchlorate ions. The results clearly show that this parameter plays an important role in the formation and in the development of superhydrophilic polypyrrole nanostructures. The proposed reaction mechanism is different from those described in the literature. It permits notably to explain the formation of polypyrrole well-oriented nanowires. The effect of the $\mathrm{pH}$ of the pyrrole solution was also highlighted. It appears that this parameter is indeed a key point for obtaining polypyrrole nanostructures since the mechanism is based on the formation of hydroxyl radicals and nanobubbles of dioxygen due to water oxidation. 


\section{References}

1. S. Aravamudhan and S. Bhansali, Sensors and Actuators B-Chemical, 2008, 132, $623-$ 630.

2. J. J. Wang, N. V. Myung, M. H. Yun and H. G. Monbouquette, Journal of Electroanalytical Chemistry, 2005, 575, 139-146.

3. L. Al-Mashat, C. Debiemme-Chouvy, S. Borensztajn and W. Wlodarski, Journal of Physical Chemistry C, 2012, 116, 13388-13394.

4. S. Sirivisoot, R. A. Pareta and T. J. Webster, in Nanocomposite Materials, ed. E. Kny, Editon edn., 2009, vol. 151, pp. 197-202.

5. T. Shoa, J. D. W. Madden, N. R. Munce and V. Yang, Polymer International, 2010, 59, 343-351.

6. M. Ates and A. S. Sarac, Progress in Organic Coatings, 2009, 66, 337-358.

7. L. F. Cui, J. A. Shen, F. Y. Cheng, Z. L. Tao and J. Chen, Journal of Power Sources, 2011, 196, 2195-2201.

8. X. Liang, Y. Liu, Z. Wen, L. Huang, X. Wang and H. Zhang, Journal of Power Sources, 2011, 196, 6951-6955.

9. J. Kim, S. I. Kim and K. H. Yoo, Biosensors \& Bioelectronics, 2009, 25, 350-355.

10. Y. Yuan, S. Zhou and L. Zhuang, Journal of Power Sources, 2010, 195, 3490-3493.

11. D. K. Ariyanayagamkumarappa and I. Zhitomirsky, Synthetic Metals, 2012, 162, 868872.

12. D. C. Zhang, X. Zhang, Y. Chen, P. Yu, C. H. Wang and Y. W. Ma, Journal of Power Sources, 2011, 196, 5990-5996.

13. K. Wang, H. Wu, Y. Meng and Z. Wei, Small, 2014, 10, 14-31.

14. S. U. Rahman, M. A. Abul-Hamayel and B. J. A. Aleem, Surface \& Coatings Technology, 2006, 200, 2948-2954.

15. T. Van Schaffinghen, C. Deslouis, A. Hubin and H. Terryn, Electrochimica Acta, 2006, 51, 1695-1703.

16. Y. Guo, Y. Zhang, H. Liu, S.-W. Lai, Y. Li, Y. Li, W. Hu, S. Wang, C.-M. Che and D. Zhu, Journal of Physical Chemistry Letters, 2010, 1, 327-330.

17. C. J. Drury, C. M. J. Mutsaers, C. M. Hart, M. Matters and D. M. de Leeuw, Applied Physics Letters, 1998, 73, 108-110.

18. C. Li, H. Bai and G. Q. Shi, Chemical Society Reviews, 2009, 38, 2397-2409.

19. Z. Yin and Q. Zheng, Advanced Energy Materials, 2012, 2, 179-218.

20. D.-H. Nam, M.-J. Kim, S.-J. Lim, I.-S. Song and H.-S. Kwon, Journal of Materials Chemistry A, 2013, 1, 8061-8068.

21. A. F. Diaz, K. K. Kanazawa and G. P. Gardini, Journal of the Chemical SocietyChemical Communications, 1979, 635-636.

22. S. Maiti, D. Das and K. Sen, Journal of the Electrochemical Society, 2012, 159, E154E158.

23. Y. F. Li, Journal of Electroanalytical Chemistry, 1997, 433, 181-186.

24. D. S. Maddison and J. Unsworth, Synthetic Metals, 1989, 30, 47-55.

25. M. Ogasawara, K. Funahashi, T. Demura, T. Hagiwara and K. Iwata, Synthetic Metals, 1986, 14, 61-69.

26. R. Y. Qian and J. J. Qiu, Polymer Journal, 1987, 19, 157-172.

27. B. T. Sun and D. P. Schweinsberg, Synthetic Metals, 1994, 68, 49-56.

28. C. Debiemme-Chouvy, Electrochemistry Communications, 2009, 11, 298-301.

29. C. Debiemme-Chouvy and T. T. M. Tran, Electrochemistry Communications, 2008, 10, 947-950. 
30. D. T. Ge, J. Mu, S. Q. Huang, P. F. Liang, O. U. Gcilitshana, S. Ji, V. Linkov and W. Shi, Synthetic Metals, 2011, 161, 166-172.

31. K. Ghanbari, S. Z. Bathaie and M. F. Mousavi, Biosensors \& Bioelectronics, 2008, 23.

32. J. Y. Huang, B. G. Quan, M. J. Liu, Z. X. Wei and L. Jiang, Macromolecular Rapid Communications, 2008, 29, 1335-1340.

33. J. Liao, C. Ning, Z. Yin, G. Tan, S. Huang, Z. Zhou, J. Chen and H. Pan, Chemphyschem : a European journal of chemical physics and physical chemistry, 2013, 14, 3891-3894.

34. J. Huang, K. Wang and Z. Wei, Journal of Materials Chemistry, 2010, 20, 1117-1121.

35. J. Zang, C. M. Li, S.-J. Bao, X. Cui, Q. Bao and C. Q. Sun, Macromolecules, 2008, 41, 7053-7057.

36. J. S. Wang, J. X. Wang, Z. Wang and S. C. Wang, Synthetic Metals, 2006, 156, 610613.

37. M. Lin, M. Cho, W.-S. Choe, J.-B. Yoo and Y. Lee, Biosensors \& Bioelectronics, 2010, 26, 940-945.

38. C. Debiemme-Chouvy, Electrochemical and Solid State Letters, 2007, 10, E24-E26.

39. C. Debiemme-Chouvy, Biosensors \& Bioelectronics, 2010, 25, 2454-2457.

40. A. Fakhry, H. Cachet and C. Debiemme-Chouvy, Journal of the Electrochemical Society, 2013, 160, D465-D470.

41. J. Wang, Y. L. Xu, F. Yan, J. B. Zhu and J. P. Wang, Journal of Power Sources, 2011, 196, 2373-2379. 